\title{
A Conditional Pan-Neuronal Drosophila Model of Spinocerebellar Ataxia 7 with a Reversible Adult Phenotype Suitable for Identifying Modifier Genes
}

\author{
Morwena Latouche, ${ }^{1,2 \star}$ Christelle Lasbleiz, ${ }^{3 *}$ Elodie Martin, ${ }^{1,2}$ Véronique Monnier, ${ }^{3}$ Thomas Debeir, ${ }^{1,2}$ \\ Annick Mouatt-Prigent, ${ }^{1,2}$ Marie-Paule Muriel, ${ }^{1,2}$ Lydie Morel, ${ }^{1}$ Merle Ruberg, ${ }^{1,2}$ Alexis Brice, ${ }^{1,2,4}$ Giovanni Stevanin, ${ }^{1,2,4}$ \\ and Hérvé Tricoire ${ }^{3}$ \\ ${ }^{1}$ Institut National de la Santé et de la Recherche Médicale, Unité 679, Paris F-75013, France, ${ }^{2}$ Université Pierre and Marie Curie-Paris 6, Institut Fédératif de \\ Recherche de Neurosciences (IFR70), Unité Mixte de Recherche (UMR) S679, Group Hospitalier Pitié-Salpêtriére, Paris F-75013, France, ${ }^{3}$ Centre National \\ de la Rechereche Scientifique, UMR 7592, Insititut Jacques Monod, Campus Universitaire de Jussieu, Paris F-75251, France, and ${ }^{4}$ Assistance Publique- \\ Hôpitaux de Paris, Groupe Hospitalier Pitié-Salpêtrière, Départment de Génétique, Cytogénétique, et Embryologie, Paris F-75013, France
}

Spinocerebellar ataxia 7 (SCA7) is a neurodegenerative disease caused by a polyglutamine (polyQ) expansion in the ataxin 7 (ATXN7) protein, a member of a multiprotein complex involved in histone acetylation. We have created a conditional Drosophila model of SCA7 in which expression of truncated ATXN7 (ATXN7T) with a pathogenic polyQ expansion is induced in neurons in adult flies. In this model, mutant ATXN7T accumulated in neuronal intranuclear inclusions containing ubiquitin, the 19S proteasome subunit, and HSP70 (heat shock protein 70), as in patients. Aggregation was accompanied by a decrease in locomotion and lifespan but limited neuronal death. Disaggregation of the inclusions, when expression of expanded ATXN7T was stopped, correlated with improved locomotor function and increased lifespan, suggesting that the pathology may respond to treatment. Lifespan was then used as a quantitative marker in a candidate gene approach to validate the interest of the model and to identify generic modulators of poly $Q$ toxicity and specific modifiers of SCA7. Several molecular pathways identified in this focused screen (proteasome function, unfolded protein stress, caspase-dependent apoptosis, and histone acetylation) were further studied in primary neuronal cultures. Sodium butyrate, a histone deacetylase inhibitor, improved the survival time of the neurons. This model is therefore a powerful tool for studying SCA7 and for the development of potential therapies for polyQ diseases.

Key words: spinocerebellar ataxia 7; Drosophila; neurodegenerative disease; inducible expression; ataxin 7; polyglutamine; neurodegeneration; ataxias; trinucleotide repeat diseases

\section{Introduction}

Spinocerebellar ataxia type 7 (SCA7), an autosomal dominant cerebellar ataxia (ADCA) associated with macular degeneration (Stevanin et al., 2000), is a polyglutamine (polyQ) disease like Huntington's disease (HD), spinobulbar muscular atrophy, den-

\footnotetext{
Received Aug. 16, 2006; revised Jan. 25, 2007; accepted Jan. 27, 2007.

This work was supported by grants from the European Community (to the European Integrated Project on Spinocerebellar Ataxias consortium, EUROSCA), VERUM Foundation (to A.B.), and the Groupement d'Intérêt Scientifique/Rare Diseases Institute (to the European Network for Hereditary Spinocerebellar Degenerative Disorders, SPATAX). Spectral confocal imaging was performed at the Plate-Forme de Recherche Institut Fédératif de Recherche-117 of the Institut Jacques Monod (Paris, France). Analyses of aggregation and disaggregation were performed with specially adapted Explora Nova software in the Imaging Plateforme of Institut National de la Santé et de la Recherche Médicale Unité Mixte de Recherche 679, with the kind assistance of Dr. Olivier Lejeune. M.L. received a fellowship from the French Ministry for Research and the French association Connaitre les Syndrômes Cérébelleux. We thank Laureline Berthelot, François Dussilol, and Stéphanie Gachet for their help, Dr. Annie Sittler for helpful discussions, Prof. Etienne-Emile Beaulieu for the gift of RU486, Prof. Jean-Louis Mandel for providing us with the $1 \mathrm{C} 1$ antibody, and Drs. Laszlo Tora and Didier Devys for antibodies against GCN5 and SPT3.

*M.L. and C.L. contributed equally to this work.

Correspondence should be addressed to Giovanni Stevanin, Institut National de la Santé et de la Recherche Médicale, Unité 679, Groupe Pitié-Salpêtrière, 47 Boulevard de I'Hôpital, 75013 Paris, France. E-mail: stevanin@ccr.jussieu.fr.

D01:10.1523/JNEUROSCI.5453-06.2007

Copyright $\odot 2007$ Society for Neuroscience $\quad 0270-6474 / 07 / 272483-10 \$ 15.00 / 0$
}

tatorubral pallidoluysian atrophy, and five other forms of ADCA (SCA1, SCA2, SCA3, SCA6, and SCA17), all of which lead to neurological dysfunction and, in most cases, death (Zoghbi and Orr, 2000; Gatchel and Zoghbi, 2005). SCA7 is caused by expansion of a polyQ tract in ataxin 7 (ATXN7) (David et al., 1997; Del Favero et al., 1998; Koob et al., 1998), a member of TATAbinding protein-free TATA-binding protein-associated factor (TAF)-containing complex (TFTC) and SPT3/TAF9/GCN5 acetyltransferase complex (STAGA) multiprotein complexes involved in histone acetylation (Helmlinger et al., 2004b; McMahon et al., 2005; Palhan et al., 2005). Proteins with expanded polyQ aggregate to form the pathological hallmark of polyQ diseases, neuronal intranuclear inclusions (NIIs), containing the mutated and other proteins. PolyQ diseases are postulated to result from a pathogenic gain of function mediated by the polyQ expansion, but the role of NIIs in the pathogenesis of the disease remains unclear: toxic (Davies et al., 1997; Scherzinger et al., 1997, 1999; Skinner et al., 1997; Becher et al., 1998; Gusella and MacDonald, 2000), nontoxic (Holmberg et al., 1998; Klement et al., 1998; Saudou et al., 1998; Sathasivam et al., 1999), or protective (Saudou et al., 1998). Cell stress markers have been 
found in NIIs in cell culture (Zander et al., 2001; Latouche et al., 2006) and mouse models of SCA7 (Yvert et al., 2000, 2001; La Spada et al., 2001; Yoo et al., 2003), but the polyQ expansion in ATXN7 may impair the activity of TFTC/STAGA complexes independently of aggregate formation (McMahon et al., 2005; Palhan et al., 2005; Strom et al., 2005).

Previous studies of polyQ diseases in Drosophila were mostly based on models in which the mutant protein was expressed ubiquitously or in the retina to facilitate screening for phenotypic modifiers (Jackson et al., 1998; Warrick et al., 1998, 2005; Fernandez-Funez et al., 2000; Marsh et al., 2000; Takeyama et al., 2002). Protein expression in these models, however, has effects on non-neuronal tissues and on development that differ notably from those in mammalians. In addition, because the sensitivity of the retina to external stress has been shown to depend on the developmental stage (Jassim et al., 2003), the use of this tissue may not always be suitable to study neurodegenerative processes affecting fully differentiated neurons. We therefore developed a model of SCA7, in which expression of truncated mutant ATXN7 (ATXN7T) is induced exclusively in neurons in adult flies. We characterized the effects of this targeted expression and determined whether the phenotype of the flies is ameliorated when expression of the pathogenic protein is stopped. Finally, we demonstrated the effectiveness of this model for screening of putative modifiers affecting the SCA7 phenotype, to elucidate pathways involved in the disease process and to design possible therapeutic strategies.

\section{Materials and Methods}

SCA7 constructs. Previously described truncated versions of the SCA7 cDNA (amino acids 1-232) (Zander et al., 2001), wild type (SCA7T10Q) and expanded (SCA7T-100Q), with an added nuclear localization signal derived from Sv40 (simian virus 40), were subcloned in pUAST (Brand and Perrimon, 1993), during which two CAG triplets were added because of instability of the sequence. All constructs were sequenced, and the size of the expressed proteins was confirmed by Western blot. Five independent transgenic lines on the $w^{1118}$ background were generated for each construct, according to standard procedures. One transgenic line was chosen for each construct on the basis of high and comparable expression levels as verified by Western blot analysis of upstream activating sequence (UAS)-SCA7T-10Q/+; da-Gal4/+ and UAS-SCA7T-102Q/+; $\mathrm{da}-\mathrm{Gal} 4 /+$ larvae with ubiquitous expression (data not shown). ATXN7T with 10Q or 100Q fused to enhanced green fluorescent protein was expressed from the pEGFP-N1 vector in cell cultures.

Fly strains, culture, and transgenic lines. All fly stocks and lines expressing the yeast transcription factor GAL4 were obtained from stock centers. Unless indicated, alleles were described previously (http://flystocks.bio.indiana.edu). All strains were maintained on standard medium at $26^{\circ} \mathrm{C}$. Ubiquitous expression was obtained with the daughterless daGAL4 line and the pan-neural expression with the elav ${ }^{c 155}$-GAL4 line (Lin and Goodman, 1994). Expression in adult neurons in the panneural inducible line (elavGS), derived from the elavGS-301.2 line described in the GeneSwitch system (Osterwalder et al., 2001), was obtained by adding mifepristone ( $\mathrm{RU} 486 ; 20 \mathrm{mg} / \mathrm{ml}$ in ethanol) to standard food, at a final concentration of $1 \%$ ethanol and $200 \mu \mathrm{g} / \mathrm{ml} \mathrm{RU} 486$. This dose induced expression to the same level as with the elav ${ }^{c 155}$-GAL4 strain (luciferase assay; data not shown). We also checked that, at this concentration, addition of RU486 has no effect on the lifespan of different lines without the presence of the elavGS driver as well as on elavGS/+ flies (data not shown).

Dissection of whole brains, adult head cryosections, and immunohistochemistry. Adult fly heads were separated from the bodies and fixed in $3.7 \%$ formaldehyde in PBS for $15 \mathrm{~min}$. Adult brains were dissected in PBS, fixed for $15 \mathrm{~min}$ in $3.7 \%$ formaldehyde in PBS, and washed for $2 \mathrm{~h}$ in PBS containing $0.5 \%$ Triton X-100 (PBST) at room temperature. After blocking in PBST containing 1\% bovine serum albumin (PBST-BSA) for
$30 \mathrm{~min}$, brains were incubated overnight at $4^{\circ} \mathrm{C}$ with the first antibody diluted in PBST-BSA, washed for $3 \mathrm{~h}$ with PBST at room temperature, incubated for $3 \mathrm{~h}$ at $4^{\circ} \mathrm{C}$ with the secondary antibody diluted in PBST$\mathrm{BSA}$, washed for $2 \mathrm{~h}$ with PBST at room temperature, and mounted in Citifluor or Vectashield (Vector Laboratories, Burlingame, CA). Brain images were acquired with a Leica (Wetzlar, Germany) TCS SP2 AOBS laser-scanning confocal microscope and processed with Adobe (San Jose, CA) Photoshop. Nuclear inclusion images were acquired with an epifluorescent microscope (Axioplan 2; Carl Zeiss SAS, Le Pecq, France) equipped with FluoUp and MorphoExpert software (Explora Nova, La Rochelle, France).

For immunofluorescence and terminal transferase-dUTP nick end labeling (TUNEL) analysis on adult head cryosections, flies were embedded in OCT (frozen tissue embedding medium) and immersed in liquid nitrogen. Sections $(5 \mu \mathrm{m})$ were cut at $-20^{\circ} \mathrm{C}$ on a Microm HM $500 \mathrm{OM}$ cryostat, dried at $37^{\circ} \mathrm{C}$, fixed in $0.5 \%$ paraformaldehyde at room temperature for $30 \mathrm{~min}$, and washed twice with PBS. Immunostaining was performed by standard techniques.

ATXN7T was detected using either the mouse anti-ATXN7 monoclonal antibody 1C1 [1:2000; a gift from J. L. Mandel, Institute of Genetics and Molecular and Cellular Biology (IGBMC), Illkirch, France] or the rabbit polyclonal anti-ATXN7 antibody (1:400; Affinity Bioreagents, Golden, CO). Other antibodies included the following: mouse antiubiquitinylated proteins (FK2; 1:200; Biomol, Plymouth Meeting, PA), rabbit anti-heat shock protein 70 (HSP70; 1:500; Stressgen Biotechnologies, San Diego, CA) and rabbit anti-19S proteasome subunit (MSS1; 1:1000; Biomol). Secondary antibodies were Alexa 488-conjugated goat anti-mouse (1:600; Invitrogen, Carlsbad, CA) and Cy3 (cyanine 3)conjugated goat anti-mouse or goat anti-rabbit (1:1000; Jackson ImmunoResearch, West Grove, PA). Tissues were counterstained with $4^{\prime}, 6^{\prime}$ diamidino-2-phenylindole dihydrochloride (DAPI) $(1 \mu \mathrm{g} / \mathrm{ml})$.

TUNEL analysis of cell death. TUNEL was performed with the ApopTag Plus Fluorescein In Situ Apoptosis Detection Kit (Millipore, Billerica, MA), according to the manufacturer's recommendations.

Immunoblotting. Whole flies and separated heads were lysed at $4^{\circ} \mathrm{C}$ in 10 mu Tris- $\mathrm{HCl}$, pH 8.0, $150 \mathrm{~mm} \mathrm{NaCl}, 5 \mathrm{~mm} \mathrm{MgCl}$, 1 mм EDTA, $1 \%$ NP-40, and $0.5 \%$ sodium deoxycholic acid supplemented with the complete protease inhibitor (Roche Diagnostics, Basel, Switzerland) and 250 $\mathrm{U} / \mathrm{ml}$ benzonase (Merck, Darmstadt, Germany), and the proteins were separated by SDS-PAGE on 12\% polyacrylamide gels followed by electrotransfer onto nitrocellulose membranes (Schleicher and Schuell BioScience, Dassel, Germany). The membranes were immunolabeled by standard techniques with peroxidase-conjugated secondary antibodies. Immunoreactivity was revealed with the Super Signal chemiluminescence kit (Pierce Biotechnology, Rockford, IL).

Electron microscopy. Transmission electron microscopy was performed on ultrathin sections of preembedding immunogold-labeled brains, as described previously (Muriel et al., 1999). Briefly, brains fixed for $4 \mathrm{~h}$ in $4 \%$ paraformaldehyde were washed in PBS, permeabilized in PBS- $0.04 \%$ Triton X-100 for $15 \mathrm{~min}$, and incubated in PBS- $0.2 \%$ BSA for $1 \mathrm{~h}$, followed by incubation at $4^{\circ} \mathrm{C}$ for $48 \mathrm{~h}$ with mouse anti-ATXN7 antibody $1 \mathrm{C} 1(1: 1000)$ and then with goat anti-mouse IgG secondary antibody ( $1: 50 ; 24 \mathrm{~h}$ at room temperature) conjugated to ultrasmall gold particles $(0.8 \mathrm{~nm}$; Aurion, Wageningen, The Netherlands). After three rinses in $2 \%$ sodium acetate $(\mathrm{w} / \mathrm{v})$, silver amplification was performed in the dark (30 min at room temperature) and then stopped by three washes in $2 \%$ sodium acetate. The signal was intensified and stabilized by immersion in $0.05 \%$ gold chloride (w/v) for $10 \mathrm{~min}$ at $4^{\circ} \mathrm{C}$ and in $0.3 \%$ sodium thiosulfate twice for $10 \mathrm{~min}$ at $4^{\circ} \mathrm{C}$. Brains were then postfixed in $2 \%$ glutaraldehyde $(20 \mathrm{~min}) / 1 \%(\mathrm{w} / \mathrm{v})$ osmium tetroxide and embedded in Epon. Ultrathin sections ( $50 \mathrm{~nm}$ thick) contrasted with uranyl acetate and lead citrate were observed with a JEOL (Akishima, Japan) 1200EX II electron microscope at $80 \mathrm{kV}$.

Evaluation of lifespan. Three-day-old adult male flies were collected in standard or RU486-containing food tubes in clusters of 30. Every $2 \mathrm{~d}$, the flies were transferred to new tubes, and the dead flies were counted. Lifespan was measured on at least 90 males per genotype and per condition. Statistical significance was determined by log rank analysis. 
A

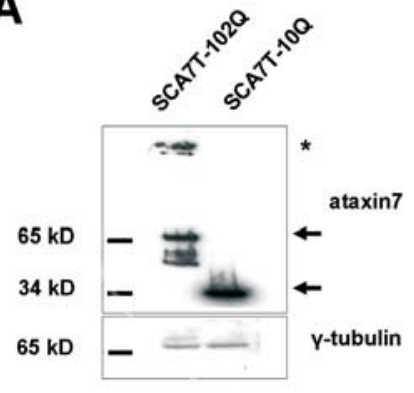

B

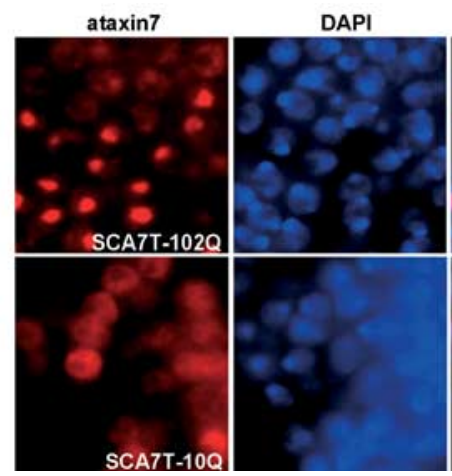

Figure 1. Expression of ATXN7T in transgenic Drosophila strains. $A$, Western blot of whole extracts (50 $\mu \mathrm{g}$ ) of larvae ubiquitously expressing ATXN7T-10Q with 10 polyglutamine repeats (UAS-SCA7T-10Q/+; da-Gal4/+) and ATXN7T-102Q with an expanded polyglutamine (UAS-SCA7T-1020/+; da-Gal4/+). The asterisk indicates SDS-insoluble polyglutamine aggregates in the stacking gel. Arrows, ATXN7T proteins expressed at the expected sizes. Note the smaller N-terminal fragments of ATXN7T1020. $\gamma$-Tubulin labeling served as the loading control. $\boldsymbol{B}$, Staining of ATXN7T (red) in neurons from the central complex of elavC ${ }^{155}$-Gal4; UAS-SCA7T-102Q/ + male flies, labeled with the 1 C1 antibody. Cell nuclei are counterstained with DAPI. ATXN7T1020 forms large inclusions in DAPI-labeled nuclei (blue), whereas ATXN7T-10Q remains diffuse in the nuclei (elavC ${ }^{155}$-Gal4; UAS-SCA7T-10Q/+ male flies). Scale bars, $5 \mu \mathrm{m}$.

Rapid iterative negative geotaxis. The rapid iterative negative geotaxis (RING) apparatus and the methods were as described previously (Gargano et al., 2005). Briefly, the ability of flies to climb up the wall of a tube after being made to fall to the bottom by tapping was expressed as the ratio of the height reached in $4 \mathrm{~s}$ by flies with induced expression of ATXN7T compared with noninduced flies of the same strain. Five consecutive tests were performed in tubes $(9.3 \times 2.2 \mathrm{~cm})$ containing 15 male flies, and the results were averaged for each genotype and condition. For kinetic studies, tests were performed with the same flies at different times after induction.

Cell cultures. Postmitotic neurons from the cortex of embryonic day 16 Wistar rats were cultured as described previously (Saudou et al., 1998). The rats were treated in accordance with the Guide for the Care and Use of Laboratory Animals (National Research Council, 1996), European Directive 86/609, and the guidelines of the local institutional animal care and use committee. MK-801 (dizocilpine maleate) $(2 \mu \mathrm{M})$ was added to prevent excitotoxicity. Glial cell proliferation was stopped with $2 \mu \mathrm{M}$ cytosine arabinoside after $3 \mathrm{~h}$. After $96 \mathrm{~h}$, the cells were transfected with the SCA7T-10Q-enhanced green fluorescent protein (EGFP) and SCA7T100Q-EGFP vectors in Lipofectamine 2000 (Invitrogen), according to the manufacturer's instructions. Control cells were transfected with the empty pEGFP-N1 vector. transfection efficiency was $\sim 3 \%$. Sodium butyrate (Millipore) was added immediately after transfection. Medium was partially replaced $(300 \mu \mathrm{l} / 500 \mu \mathrm{l})$ every $2 \mathrm{~d}$ with fresh medium containing appropriate concentrations of sodium butyrate. Seven days after transfection, the percentage of dead transfected cells was evaluated by ETH-D1 (ethidium homodimer-1) staining (LIVE/DEAD CellMediated Cytotoxicity Kit; Invitrogen) in 100 randomly chosen EGFPpositive neurons per well. The results are expressed as the mean \pm SEM of three independent experiments performed in duplicate.

Immunofluorescence on cell cultures. Cortical neurons, cultured as above on four-well culture slides (BD Biosciences, San Jose, CA) coated with polyethyleneimine, were fixed for $15 \mathrm{~min}$ with $4 \%$ formaldehyde $4 \mathrm{~d}$ after transfection. ATXN7T-100Q-EGFP was observed directly. Immunocytochemistry was performed as described previously (Latouche et al., 2006) with the antibodies described above and rabbit anti-activated caspase 3 (Asp 175; 1:100; Cell Signaling Technology, Beverly, MA). Antibodies against GCN5 (mouse anti-GCN5; 1:200) and SPT3 (mouse anti-SPT3; 1:250) were both gifts from D. Devys (IGBMC). Cells were counterstained with DAPI $(1 \mu \mathrm{g} / \mathrm{ml})$, mounted with Fluoromount-G, and observed with a Leica SP1 confocal microscope. Leica confocal software was used to acquire the images. merged

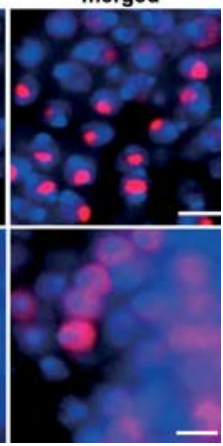

\section{Results \\ Human ATXN7T is expressed and processed normally in transgenic Drosophila}

We showed previously that the transgenes encoding truncated forms (amino acids 1-232) of wild-type (SCA7T-10Q) and mutant (SCA7T-100Q) ATXN7 are expressed at higher levels, and the resulting proteins aggregate faster than full-length ATXN7 in human cells in culture (Zander et al., 2001). We have now used these transgenes to generate SCA7 Drosophila. Another SCA7 fly was generated previously using full-length ATXN7 with $90 \mathrm{Q}$ (Jackson et al., 2005), but no obvious phenotype was observed (Albert R. La Spada, personal communication). Interestingly, previous studies described an abundant $\mathrm{N}$-terminal cleavage fragment of expanded ATXN7 in mouse models of SCA7 (Yvert et al., 2000; Garden et al., 2002) and in fibroblasts of a juvenile-onset SCA7 patient (Garden et al., 2002). Moreover, it has been shown that ATXN7 is cleaved by caspase 7 (Ellerby et al., 1999) at positions 266 and 344, thus modulating its cytotoxicity (Garden et al., 2006). The truncated N-terminal form of ATXN7 that we used, containing amino acids $1-232$, is close to the shortest natural fragment observed and should therefore be relevant to the study of SCA7 pathology.

Because ATXN7 is widely expressed in humans (David et al., 1997; Cancel et al., 2000), but alterations are only observed in neurons, expression of the transgenes was targeted both ubiquitously using the da-GAL4 strain and in all neurons of the peripheral nervous system and CNS using the elav ${ }^{\mathrm{C} 155}$-GAL4 line. To determine whether the truncated forms of human ATXN7 are expressed and processed normally in Drosophila, ATXN7T expression in the SCA7T-10Q and SCA7T-102Q da-GAL4 lines were analyzed on Western blots of larval extracts. Soluble proteins of appropriate apparent molecular weights were detected, as well as aggregated forms of ATXN7T-102Q, which remained in the stacking gel (Fig. 1A). Smaller fragments of ATXN7T-102Q were also detected, as observed previously with the same constructs in models using human cells (Zander et al., 2001), suggesting that the protein is normally processed in vivo.

Neuron-specific expression of ATXN7T in the elav ${ }^{\mathrm{C} 155}$-GAL4 flies was analyzed by immunofluorescence in the brains of 10-dold flies. Both transgenes were highly expressed at similar levels throughout the CNS (data not shown). ATXN7T-10Q labeling was diffuse in neuronal nuclei, whereas ATXN7T-102Q aggregated in large NIIs (Fig. 1B), showing that human ATXN7T is expressed and processed normally in Drosophila neurons and that the mutant protein forms intranuclear aggregates as in patients.

Expression of SCA7T-10Q under control of da-Gal4 or elav ${ }^{\mathrm{C} 155}$-GAL4 drivers did not affect the rate of emergence. In addition, neuronal expression of this protein with the driver line elav ${ }^{\mathrm{C} 155}$-GAL4 has little or no toxicity, because the lifespan of elav ${ }^{\mathrm{C} 155}$-GAL4; SCA7T-10Q/+ flies [half-life $(\mathrm{T} 50)=45 \mathrm{~d}$ ] is intermediate between that of flies with either of the two control genotypes SCA7T-10Q/+ $(\mathrm{T} 50=43 \mathrm{~d})$ or elav ${ }^{\mathrm{C} 155}-\mathrm{GAL} 4$ $(\mathrm{T} 50=54 \mathrm{~d})$. In contrast, SCA7T-102Q expression was lethal to 


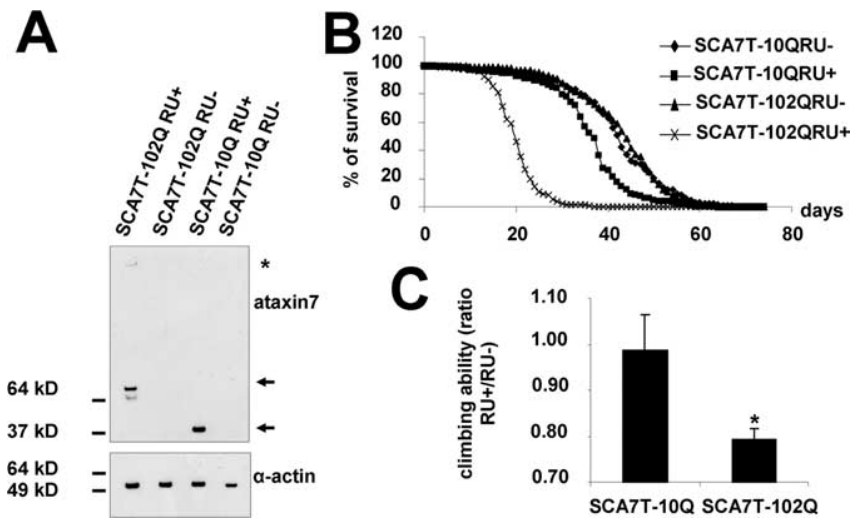

Figure 2. Induced expression of mutant ATXN7T in adult Drosophila neurons decreases locomotor activity and lifespan. $\boldsymbol{A}$, Western blot of whole extracts of heads from 15 -d-old male flies (UAS-SCA7T-10Q/+; elavGS/+ and UAS-SCA7T-102Q/+; elavGS/+) in which expression of ATXN7T-10Q and ATXN7T-102Q was induced (RU +) or not induced (RU-) with RU486. The asterisk indicates SDS-insoluble polyQ aggregates in the stacking gel. Arrows, ATXN7T proteins expressed at the expected sizes. When overexposed, a thin band of ATXN7T was detected in the absence of RU486, indicating a slight leak in the control of expression. $\boldsymbol{B}$, Lifespan of flies expressing or not expressing ATXN7T-10Q and ATXN7T-102Q in adult neurons. Note that ATXN7T-102Q expression strongly reduced lifespan (log rank analysis; $p<10^{-50}$ ), whereas ATXN7T-10Q expression had only a slight effect $\left(p<10^{-10}\right)$. RU486 had no effect on longevity in wild-type flies (data not shown). C, Locomotor activity (performance on RING test) of 16-dold flies expressing or not expressing ATXN7T-10Q and ATXN7T-1020 transgenes. * Significantly different from the ATXN7T-10Q condition ( $p=0.006$; Student's $t$ test). Error bars represent SEM.

larvae when ubiquitously expressed with the da-GAL4 driver and partially lethal when expressed only in neurons. In the latter case, it also strongly reduced the lifespan of adult elav ${ }^{\mathrm{C} 155}$-GAL4; SCA7T-102Q $/+$ flies $(\mathrm{T} 50=5.5 \mathrm{~d})$. These data suggest that, in addition to the effect of neuronal SCA7T-102Q expression on survival, some non-neuronal cells also contributed to lethality in da-Gal4; SCA7T-102Q/+ flies. Accordingly, expression of a SCA7T-102Q transgene under control of a muscle-specific driver, 24B-GAL4, strongly reduced the lifespan of the flies $(\mathrm{T} 50=7 \mathrm{~d})$. To distinguish between developmental defects induced by mutant ATXN7T and neuronal dysfunction in adult cells, we developed a model in which mutant ATXN7T can be inducibly expressed in the adult.

\section{Mutant human ATXN7T decreases lifespan when} conditionally expressed in adult Drosophila neurons

SCA7 Drosophila were created with the elavGS transgene, in which expression of ATXN7T-10Q and ATXN7T-102Q can be induced in neurons in adult flies by RU486 added to their food. Flies from the same batch fed with normal food served as controls. ATXN7T was strongly expressed in flies treated with RU486 as detected by Western blot (Fig. $2 \mathrm{~A}$ ), and only a very weak signal was detected in the absence of RU486 (after much longer exposure times), confirming that expression depended on the presence of RU486. The elavGS transgene was also tested in an in vivo luciferase assay using a UAS-luciferase strain. Without RU486, only a low level of expression, just above background, was observed. With RU486, induction of the luciferase reporter was 10-fold higher (data not shown).

Flies that expressed ATXN7T-102Q died between days 10 and 30 after the beginning of induction (Fig. 2 B) (T50 = $19.6 \mathrm{~d}$ ). If expression of ATXN7T-102Q was not induced, lifespan was increased (Fig. $2 B)\left(\mathrm{T} 50=43.6 \mathrm{~d} ; p<10^{-30}\right.$ compared with induced flies). The lifespan of flies in which expression of
ATXN7T-10Q was induced (Fig. 2B) $($ T50 = 36.5 d) was also slightly decreased compared with noninduced controls (Fig. $2 B$ ) $\left(\mathrm{T} 50=42.1 \mathrm{~d} ; p<10^{-10}\right)$, as shown previously in another polyQ disease (Fernandez-Funez et al., 2000). The presence of the human ATXN7T (10Q or 102Q), therefore, affects the longevity of elavGS Drosophila, particularly when the polyQ tract is expanded.

\section{Expression of mutant ATXN7T in adult Drosophila neurons} causes locomotor dysfunction and limited cell death

To determine whether expression of mutant ATXN7T causes neurological dysfunction in adult flies before it compromises survival, climbing ability was assessed by RING analysis, as described previously (Gargano et al., 2005), $10 \mathrm{~d}$ (data not shown) and $16 \mathrm{~d}$ (Fig. 2C) after induction of ATXN7T-10Q and ATXN7T-102Q expression by RU486. ATXN7T-102Q expression decreased locomotor activity at both time points compared with the noninduced controls, whereas ATXN7T-10Q had little or no effect. Similar to the effect on lifespan, overexpression of ATXN7T with a polyQ expansion caused neurological dysfunction.

To assess whether the effects of mutant ATXN7T on lifespan and behavior resulted from neuronal death, we TUNEL labeled nicked DNA in dead or dying cells. Eighteen days after induction of ATXN7T-102Q expression, a few TUNEL-positive cells were observed in fly brains, most notably in the optic lobes (Fig. $3 A, B$ ), but none were observed without induction (Fig. $3 B$ ). Because expanded ATXN7T caused little detectable neurodegeneration, the behavioral abnormalities and the premature death of ATXN7T-102Q-expressing flies likely also resulted from cellular dysfunction. We therefore investigated the protein content and ultrastructure of the NIIs, to try to determine how they might impair cell function.

\section{NII formation in Drosophila expressing mutant ATXN7T in adult neurons}

ATXN7T-positive structures in neuronal nuclei of flies expressing ATXN7T-102Q were coimmunolabeled, $15 \mathrm{~d}$ after induction, with antibodies against ubiquitin, the 19S subunit of the proteasome, and the chaperone HSP70, proteins that are found in NIIs in SCA7 patients (Zander et al., 2001; Takahashi et al., 2002; Latouche et al., 2006). All three proteins colocalized in NIIs with mutant ATXN7T, recapitulating a major feature of SCA7 (Fig. 3C).

To determine whether these structures were fibrillar, as shown previously in cell culture (Zander et al., 2001), their ultrastructure was examined. Very large $(\approx 2 \mu \mathrm{m})$, round ATXN7T/ immunogold-labeled fibrillary nuclear structures that excluded chromatin were observed (Fig. 3D). The chromatin retained a normal appearance, however, as did the nuclear membrane and mitochondria (Fig. 3D).

\section{The deleterious effects of ATXN7T-102Q are partially reversible}

To treat polyQ diseases, the effects of the mutant protein must be reversible or repressible. This could be tested in our model, because expression of ATXN7T-102Q could be arrested by withdrawal of RU486. We compared the phenotype (lifespan, RING test performance, and aggregation) in flies in which expression of ATXN7T-102Q was induced and maintained and flies in which expression was induced for 2 or $4 \mathrm{~d}$ and then arrested. Controls were noninduced flies.

When RU486 was withdrawn after $4 \mathrm{~d}$, lifespan increased significantly compared with flies continuously expressing ATXN7T-102Q. Lifespan increased further if RU486 was with- 
A

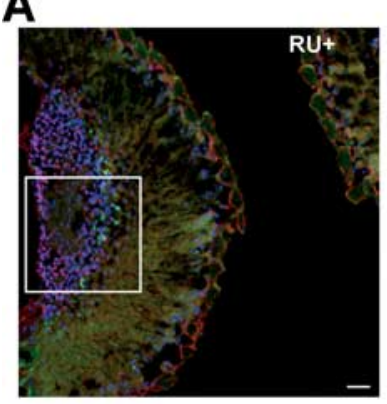

B $\quad \operatorname{ataxin} 7$

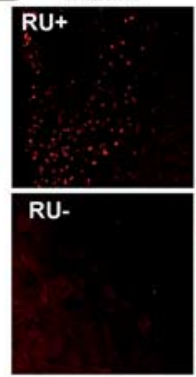

TUNEL
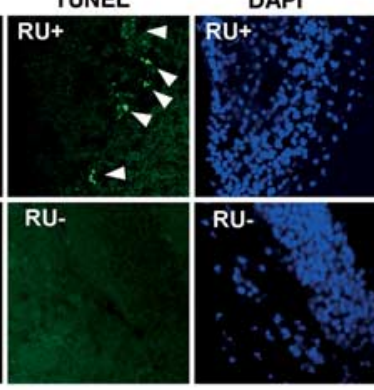

C

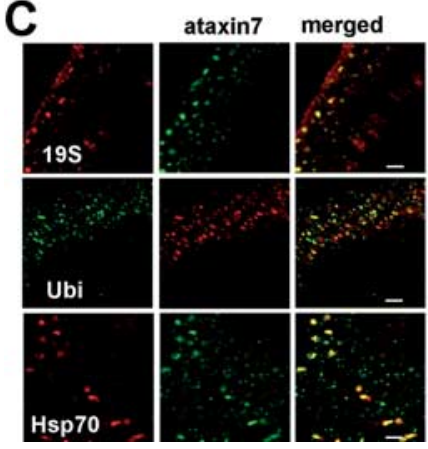

D

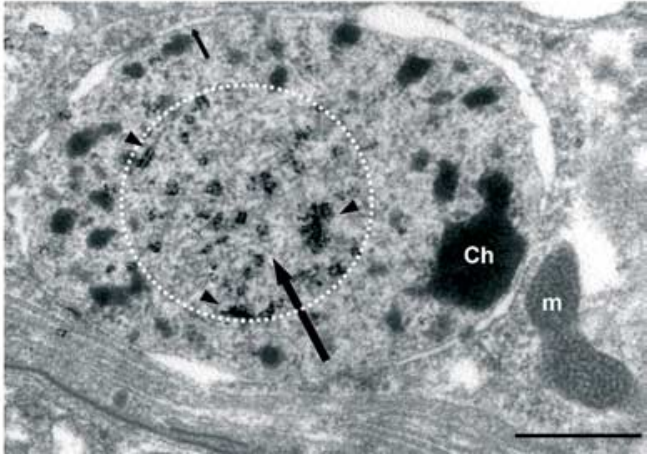

Figure 3. Adult neurons in Drosophila expressing mutant ATXN7T do not degenerate massively but contain NIIs. $A, B$, Neuronal death was assessed by TUNEL analysis 18 d after induction (RU + ), or not (RU-), of ATXN7T-10Q (UAS-SCA7T-10Q/+; elavGS/+) and ATXN7T-102Q (UAS-SCA7T-102Q/+; elavGS/+) expression. A, Overview of a brain section from a fly expressing ATXN7T102Q, showing mutant ATXN7T (red) in nuclei (blue) of neurons. A cluster of TUNEL-positive (green) nuclei can be seen on the edge of the optic lobes (boxed). A low level of autofluorescence can be seen throughout the section. Scale bar, $20 \mu \mathrm{m}$. B, Enlarged view of boxed area in $A$ compared with an equivalent area from a SCA7T-102Q transgenic fly in which expression of the transgene was not induced and in which no TUNEL-positive cells (arrowheads) were seen. Scale bars, $10 \mu \mathrm{m}$. C, Colocalization of ATXN7T, shown here in the optic lobes of UAS-SCA7T-1020/+; elavGS/+ male flies, with the 195 proteasome subunit, ubiquitin (Ubi), and HSP70. Images in $\boldsymbol{B}$ and $\boldsymbol{C}$ were obtained by spectral confocal microscopy. Scale bars, $10 \mu \mathrm{m}$. $\boldsymbol{D}$, Ultrastructure of a nucleus containing immunogold-labeled mutant ATXN7T (black dots indicated by black arrowheads) in the Kenyon cell region of UAS-SCA7T$1020 /+$; elavGS/ + male flies. The very large $(\approx 2 \mu \mathrm{m})$ fibrillary aggregate of mutant ATXN7T (white dashed circle) is composed of thin $(\approx 0.3 \mu \mathrm{m})$ interwoven fibrils (large black arrow) of ATXN7T. The nuclear membrane (small black arrow), mitochondria $(\mathrm{m})$, and chromatin (Ch) appear normal. Scale bar, $1 \mu \mathrm{m}$.

drawn after $2 \mathrm{~d}\left(p<10^{-29}\right)$ but remained shorter than the lifespan of noninduced flies (Fig. 4A). RING test performance, $16 \mathrm{~d}$ after induction, reached control levels when RU486 was withdrawn after $2 \mathrm{~d}$, and remained identical to the noninduced control at all later time points $(18,21$, and $25 \mathrm{~d})$. When RU486 was withdrawn after $4 \mathrm{~d}$ of induction, the climbing ability of the flies was reduced but was significantly better, $18 \mathrm{~d}$ after induction, than in flies continuously expressing ATXN7T-102Q and remained stable at 21 and $25 \mathrm{~d}$ after induction (Fig. $4 \mathrm{~B}$ ).

The proportion of ATXN7T-102Q-positive neurons with large NIIs, visible after $2 \mathrm{~d}$ of expression, remained constant from day 2 to day 20 in continuously treated flies (Fig. 4C, black bars). In flies deprived of RU486 from day 2, nuclear labeling became progressively more diffuse, suggesting that soluble ATXN7T was present, and the remaining NIIs were smaller (Fig. $4 C$, white bars) (supplemental figure, available at www.jneurosci.org as supplemental material), as if NIIs were being cleared or disaggregated in the absence of continued synthesis of the mutant protein. A drastic decrease in the percentage of neurons with large NIIs was observed from day 14 to day 20 in flies in which RU486 was withdrawn after $2 \mathrm{~d}$ (Fig. 4C), indicating that elimination of the aggregates was slow and may depend on the presence of a threshold amount of polyQ-expanded protein. Later time points could not be examined because of the effect of the mutant protein on lifespan. The fact that these flies continued to die, albeit later than merged

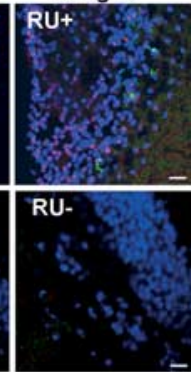

those expressing ATXN7T-102Q continuously, confirms, however that the level of mutant ATXN7T at that time was enough to initiate irreversible pathogenic events. These results show that a decrease in ATXN7T expression improves the phenotype (lifespan and locomotion) of SCA7 flies in correlation with a decrease in ATXN7T aggregation. These results demonstrate that it is possible to alter the phenotype of our model, which may therefore be used to identify modifier genes that are possible therapeutic targets.

\section{Modulators of SCA7T-102Q toxicity}

Retinal phenotypes of polyQ models, which are practical (Warrick et al., 1998, 2005; Fernandez-Funez et al., 2000; Kazemi-Esfarjani and Benzer, 2000; Steffan et al., 2001; Ravikumar et al., 2004), are not always reproduced in brain (Ghosh and Feany, 2004). Our inducible panneuronal Drosophila SCA7T-102Q line is ideally suited to identify modifiers of the SCA7 phenotype, because it isolates the effect of the mutation on adult neurons, in which pathology is observed in patients, and avoids effects related to development, which differ significantly between humans and flies. Lifespan quantification was used to assess the effect of putative modulators of the SCA7 phenotype. Males from our fly line inducibly expressing mutant ATXN7T were crossed with females from 36 different strains characterized by the enhancement or disruption of genes that, by their function, may modulate expression of the ATXN7T-102Q phenotype (supplemental Table 1, available at www.jneurosci.org as supplemental material). This focused screen was performed to determine whether the model constitutes a powerful tool for identifying putative therapeutic targets. We verified that the effects of the identified modifier strains were not attributable to altered UAScontrolled expression of ATXN7T-102Q by an in vivo GAL4induced luciferase assay (data not shown).

The results suggest that activation of the ubiquitin proteasome pathway, inhibition of caspase activity, activation of the unfolded protein response, and some transcription regulators may favorably modulate the SCA7 phenotype (Table 1).

Four strains with mutations affecting the caspase pathway, transcription factor, and RNA-binding protein categories significantly enhanced the SCA7 phenotype. One was a loss-offunction IAP1 (inhibitor of apoptosis 1) mutant that increases apoptosis-related caspase activity. Paradoxically, a loss-offunction mutation of the ced6 gene, implicated in the engulfment of apoptotic cells, was found among the significant suppressors. Identification of the transcriptional regulators Rpd3 (gain of function) and CBP [CREB (cAMP response element-binding protein)-binding protein] (loss of function) among the modulators suggested that histone acetylation may be affected in SCA7 flies. None of these proteins reduced lifespan by themselves in the absence of an SCA7-102Q insertion (supplemental Table 1, available at www.jneurosci.org as supplemental material). Fur- 
thermore, mutant forms of Taf10 and dTra1 (loss of function) (members of the transcriptional SAGA-like complex, an orthologue of the TFTC/STAGA complexes containing ATXN7 in mammals) modified the phenotype, although dAda3 (gain of function) or Spt3 (loss of function), which are part of the same complex, did not. Interestingly, reducing the expression of ATXN2, the polyQ protein responsible for SCA2, strongly protected against mutant ATXN7T.

Finally, some of the tested genes were shown previously to modify the SCA1 phenotype (Table 1) (supplemental Table 1, available at www.jneurosci.org as supplemental material). Only one, $R p d 3$, which is disrupted, enhanced the SCA7 phenotype. Curiously, upregulation of the mRNA splicing regulator $m u b$, which previously suppressed the SCA1 phenotype (FernandezFunez et al., 2000), enhanced the SCA7 phenotype. However, we found that expression of $m u b$ alone in adult neurons with the elavGS driver significantly reduced lifespan (supplemental Table 1, available at www. jneurosci.org as supplemental material). This suggests that the enhancement of the SCA7 phenotype may result from an additive deleterious effect, although we cannot exclude that SCA7 flies are also sensitive to perturbation of splicing.

\section{Analysis of mammalian neurons in culture supports the implication of putative modifier genes in SCA7}

To confirm the validity of our focused genetic screen, we first immunolabeled primary cultures of embryonic rat cortex expressing truncated EGFP-tagged SCA7T100Q with antibodies against markers of the ubiquitin/proteasome pathway (19S proteasome subunit and ubiquitin), the unfolded protein stress pathway (HSP70), caspase-dependent apoptosis (activated caspase 3), and the TFTC/STAGA complexes (GCN5, SPT3, and SPT7). All of these proteins except one (SPT7; data not shown) colocalized with ATXN7T in NIIs (Fig. 5A), supporting the hypothesis that they may be implicated in SCA7 pathogenesis.

Because ATXN7 is found in TFTC/

STAGA transcriptional complexes, which have histone acetyltransferase activity, we evaluated the effect of increasing concentrations $(10-100 \mu \mathrm{M})$ of the presently most promising histone deacetylase (HDAC) inhibitor for treating polyQ diseases, sodium butyrate (SB), on the survival of cultured neurons expressing EGFP, ATXN7T-100Q-EGFP, and ATXN7T-10Q-EGFP (Ferrante et al., 2003; Minamiyama et al., 2004; Ying et al., 2006). Seven days after transfection, the cells were stained with the cell death marker ethidium homodimer-1, and the percentage of dead EGFP-, ATXN7T-10Q-EGFP-, and ATXN7T-100Q-EGFP-positive cells was calculated. In the absence or presence of 10 and $50 \mu \mathrm{M} S B$, a low of SCA7 flies

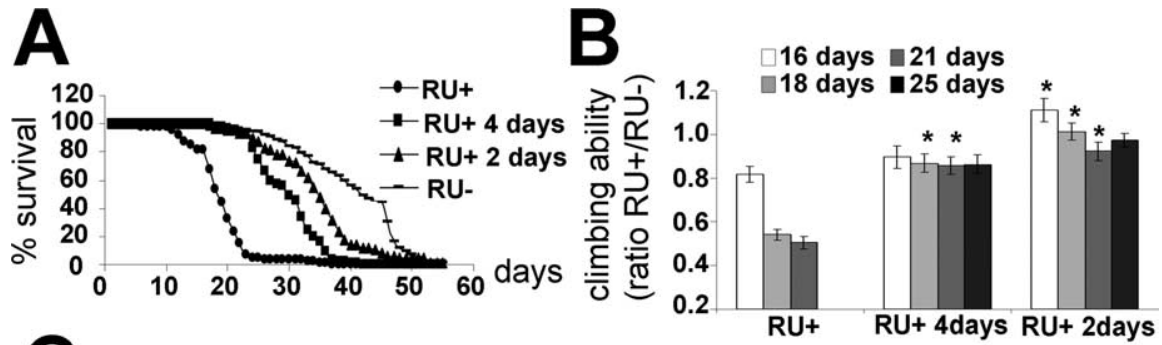

Figure 4. Lifespan, locomotor activity, and ATXN7T aggregation improve when expression of ATXN7T-1020 is stopped in UAS-SCA7T-102Q/+ ; elavGS/ + male flies. $\boldsymbol{A}$, Lifespan when ATXN7T-102Q was not induced (control: RU-), induced continuously with RU486 (RU+), or induced for $2 \mathrm{~d}(\mathrm{RU}+2$ days) or $4 \mathrm{~d}(\mathrm{RU}+4$ days). Lifespan was inversely correlated with the duration of RU486 treatment $\left(p<10^{-20}\right)$. B, RING test at $16,18,21$, and $25 \mathrm{~d}$ after induction. Locomotor performance was expressed as strain. At 18 and $21 \mathrm{~d}$ after induction, it was better in flies treated for $4 \mathrm{~d}$ with RU486 than in those treated continuously, and it remained at control levels at all time points if treatment lasted only $2 \mathrm{~d}(\mathrm{RU}+2 \mathrm{~d} / \mathrm{RU}-=1 \pm 0.1) .{ }^{*} p<0.005$, significantly be performed, because the continuously treated flies were already dead. C, Proportion of large NIIs in ATXN7T-positive neurons reated continuously ( $p<0.05$; 2-way ANOVA, followed by the Student-Newman-Keuls test for multiple comparisons). There

Table 1. Modifier strains of Drosophila issued from the candidate gene screening for modulators of the lifespan

\begin{tabular}{llll}
\hline Gene & Function & Simplified genotype $^{a}$ & Effect $^{b}$ \\
\hline Uba1 & Ubiquitin proteasome system & Uba1[UY3010] & Su \\
Rpn11 & Ubiquitin proteasome system & Rpn11[BG01694] & Su \\
DNAJ-H & Chaperone & PUAS-DNAJ[1] & Su \\
DIAP1 & Caspase pathway & DIAP1[UY1156] & Su \\
DIAP1 & Caspase pathway & th[EY00710] & Su \\
DIAP1 & Caspase pathway & Th[j5C8] & En \\
Ced6 & Apoptosis engulfment & ced-6[KG03411a] & Su \\
HSC70 & Unfolded protein response & PUAS-Hsc703 & Su \\
Taf10 & Transcription complex & Taf10[KG07031] & Su \\
Tra1 & Transcription complex & Nipped-A[NC116] & Su \\
CBP & Transcriptional cofactor & EP950 & En \\
Rpd3 & Transcriptional cofactor & EP3672 & En \\
mub & RNA-binding protein ${ }^{d}$ & EP3623 & En \\
ATX2 & Actin filament formation & ATX2[06490] & Su \\
\hline
\end{tabular}

${ }^{a}$ The full genotype is given in supplemental Table 2 (available at www.jneurosci.org as supplemental material).

${ }^{b}$ Effects were considered significant only if enhancement (En) or suppression (Su) of the lifespan was $>15 \%$ and $p$ was $<0.001$.

'Enhanced the SCA1 phenotype in a previous study (Fernandez-Funez et al., 2000).

${ }^{d}$ Suppressed the SCA1 phenotype in a previous study (Fernandez-Funez et al., 2000).

level of cell death was observed in transfected cells expressing EGFP alone $(6 \%)$ or ATXN7T-10Q-EGFP (12\%), whereas $100 \mu \mathrm{M}$ SB was toxic in itself (Fig. 5B). Neuronal death induced by ATXN7T-100QEGFP ( $\sim 34 \%)$ decreased significantly, however, in the presence of both $10 \mu \mathrm{M}(26 \%)$ and $50 \mu \mathrm{M}(20 \%) \mathrm{SB}$, suggesting that a decrease in histone deacetylation compensates for a decrease in histone acetylation potentially caused by mutant ATXN7T. Unfortunately, our transfection efficiency ( $3 \%$ ) did not allow us to assess modifications of histone acetylation in the neurons expressing ATXN7T-100QEGFP nor to demonstrate a decrease in the activity of the SAGA-like complexes. 

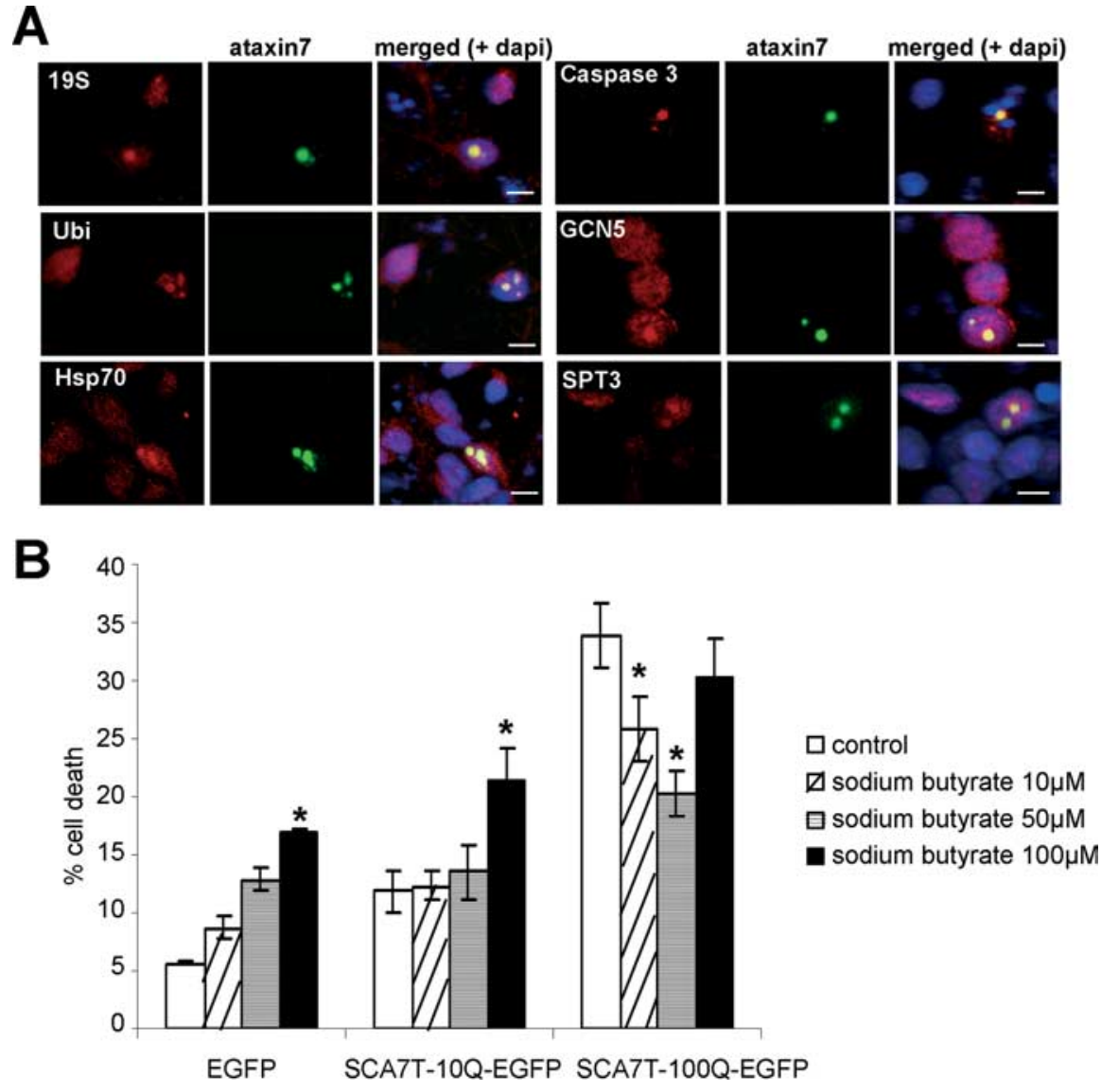

Figure 5. Proteins involved in the SCA7 phenotype in Drosophila are relocated into NIls in mammalian neurons expressing mutant ATXN7T, and sodium butyrate alleviates fly neuronal death. $\boldsymbol{A}$, Spectral confocal microscopic images showing colocalization in NIls of ATXN7T with protein markers of modifier pathways identified in this study: the 19S proteasome subunit, ubiquitin (Ubi), HSP70, activated caspase 3, and components of the mammalian histone acetylation STAGA complex (GCN5 and SPT3). Scale bars, $5 \mu \mathrm{m}$. $\boldsymbol{B}$, The cytotoxicity of ATXN7T-100Q-EGFP, ATXN7T-10Q-EGFP, and EGFP alone was evaluated in the presence or the absence of the HDAC inhibitor SB. *Significantly different from untreated cells ( $p<0.001$; 1-way ANOVA, followed by the Student-Newman-Keuls test for multiple comparisons). Error bars represent SEM.

\section{Discussion}

A Drosophila model that reproduces major features of SCA7 With the RU486-inducible GeneSwitch system, we developed a conditional model of SCA7 in Drosophila, in which expression of a truncated $\mathrm{N}$-terminal form of the protein, close in size to the shortest naturally occurring fragment observed (Garden et al., 2006), could be induced in flies that had already reached adulthood. This avoided the confounding, and often lethal, effects of mutant ataxin-7 on development, during larval and pupal stages, which have no equivalent in mammals. Coupled with the panneuronal elav promoter, this system enabled us to express the pathogenic protein specifically in neurons. Flies expressing the transgene rapidly accumulated mutant ATXN7T in fibrillary aggregates associating stress-related proteins that resembled the NIIs observed in patients, suffered a progressive loss of locomotor function, and died prematurely. In this model, normal ATXN7T was also slightly toxic, in accordance with previous reports (Fernandez-Funez et al., 2000). Apart from the NIIs, no other cellular anomalies were detected at the ultrastructural level up to $15 \mathrm{~d}$ after induction, and little neuronal loss occurred, as evaluated by TUNEL analysis. Cellular dysfunction, therefore, contributes to the behavioral phenotype and premature death of the ATXN7T-102Q flies, as was also the case in SCA1 mice (Clark et al., 1997; Skinner et al., 2001). An absence of significant neu- ronal loss was also observed in mouse models of Huntington's disease (Mangiarini et al., 1996; Shelbourne et al., 1999; Usdin et al., 1999; Yamamoto et al., 2000; Martin-Aparicio et al., 2001) and SCA7 (Yvert et al., 2000, 2001; Garden et al., 2002; Yoo et al., 2003).

\section{The pathophysiology of SCA7}

The progression of the pathology in the present model, as in other models of SCA7 (Helmlinger et al., 2004a), HD (Yamamoto et al., 2000; Martin-Aparicio et al., 2001; Regulier et al., 2003), and SCA1 (Zu et al., 2004), was correlated with aggregation of the protein. Interestingly, expression of mutant ATXN7T for only $2 \mathrm{~d}$ was sufficient to generate NIIs and shorten the lifespan of the SCA7 flies, although effects on survival and locomotor activity were observed much later.

Because expression of the transgene could be stopped in our SCA7 Drosophila, we were able to determine that NIIs disaggregate slowly if the mutant protein is not continually expressed, and this was correlated with long-term stabilization of the motor phenotype and an increase in lifespan. The stable amelioration of the phenotype observed when expression of the pathogenic protein was limited in time indicates that progression of the pathology was efficiently arrested. The inclusions persisted, however, at least $8 \mathrm{~d}$ after RU486 was withdrawn, and the mutant protein remained present in dispersed form in nuclei, even after the NIIs disaggregated. This shows that clearance of mutant ATXN7T is slow, confirming a previous report (Helmlinger et al., 2004a), compared with huntingtin (Martin-Aparicio et al., 2001) and particularly ataxin 1 (Zu et al., 2004).

In contrast to our transgenic Drosophila, transgenic SCA7 mice did not recover but continued to worsen when expression of mutant SCA7 was stopped (Helmlinger et al., 2004a), probably because of the continued presence ( $>26$ weeks) of aggregates; mutant ATXN7 was processed more slowly in these mice than in Drosophila. Similar observations were made in a conditional transgenic model of SCA1, in which the more the transgene was expressed, the more the pathology worsened, and the less the animals recovered ( $\mathrm{Zu}$ et al., 2004). Reversion of neurological dysfunction, as in our model, was, therefore, associated with the disappearance of intranuclear aggregates, whereas a worsening of the phenotype was associated with the persistence of aggregates. It is possible, therefore, that if aggregates sequester pathogenic proteins, their disappearance might indicate that the toxic species has been eliminated.

\section{Putative modulators of SCA7 phenotype and potential therapies}

Because our conditional Drosophila model isolates the effects of mutant ATXN7T on adult neurons and has a phenotypic trait, lifespan, that can be quantified, we were able to perform a candi- 
date gene screen to demonstrate that the model can be used to identify neuronal pathways that are involved in the expression of the pathology or its reversion. Our study indicates that protein folding, histone acetylation, the ubiquitin proteasome pathway, and apoptosis, which are features common to several polyQ disease models (Ghosh and Feany, 2004), are also implicated in SCA7. Major protein markers of these pathways (19S proteasome subunit, ubiquitin, HSP70, and activated caspase 3) are relocated to NIIs in SCA7 Drosophila but also in mammalian neurons in vitro, supporting this hypothesis and suggesting the existence of common triggering mechanisms. Our study also confirmed another genetic modifier identified previously in Drosophila models of polyQ diseases (Ghosh and Feany, 2004) and tauopathy (Shulman and Feany, 2003), ATXN2, which, when mutated, causes SCA2 (Imbert et al., 1996; Pulst et al., 1996; Sanpei et al., 1996). This suggests that the normal function of ATXN2, which is not precisely known (Satterfield et al., 2002; Ralser et al., 2005a,b), might be implicated in the physiopathology of several, if not all, polyQ diseases. This would be similar to the TATA-binding protein, which causes SCA17 when it contains a polyQ expansion, but also plays a role in other polyQ diseases (Roon-Mom et al., 2005).

The Toll- and imd-mediated NF- $\kappa \mathrm{B}$ (nuclear factor $\kappa \mathrm{B}$ ) pathways that regulate the transcription of survival genes, examined for the first time here in a polyQ disease model, do not seem to be involved in ATXN7T-102Q pathology. The role of the unfolded protein response (UPR) in our model is still not clear, because reducing gene dosage of the upstream regulator ire 1 or upregulation of the translation regulator $d$ Perk (diphosphorylated extracellular signal-regulated kinase) kinase did not modify the phenotype. In contrast, Hsc70-3 [Drosophila homolog of the downstream UPR target Bip (Ig-binding protein)/Grp78 (glucose-regulated protein)] was protective when overexpressed. Because the IRE1-TRAF2 (TNF-receptor-associated factor 2)ASK1 (apoptosis signal-regulating kinase 1) complex has been implicated in polyQ pathology in mammalian cell culture experiments (Nishitoh et al., 2002), our findings might be specific to SCA7, but this remains to be confirmed.

Because the transcriptional complex TFTC/STAGA contains ATXN7 in mammals, we investigated what happens when the activity of the corresponding SAGA-like complex in Drosophila is impaired. Interestingly, reducing the dosage of Taf 10 and dTRA1 rescued the phenotype, identifying a new pathway specifically involved in SCA7. ATXN7 was shown to interact with TFTC/ STAGA subunits through a Zinc-binding domain formed by highly conserved Cys and His residues, which can be found in conserved blocks I and II (Helmlinger et al., 2004b). The ATXN7T we used contains block I but not block II. Although a direct interaction between this block and the TFTC/STAGA complexes has not been demonstrated, the identification of members of this complex as modifier genes in flies and their colocalization with truncated ataxin 7 in mammalian neurons suggest that the function of this truncated protein or its capacity to interact with these complexes, like the full-length protein, may be at least partially conserved. Because mutant ATXN7 represses the acetyl transferase activity of the complex, according to recent studies (McMahon et al., 2005; Palhan et al., 2005), or leads to a transcriptional downregulation of genes encoding members of the complex (Palhan et al., 2005; Strom et al., 2005; Helmlinger et al., 2006), our results suggest that the concentrations of the subunits are important for the assembly and activity of the complex and that members of the TFTC/STAGA transcriptional complexes might be interesting therapeutic targets. This was further sup- ported by the partial relocation of some proteins of the TFTC/ STAGA complexes to NIIs (GCN5 and SPT3) in primary mammalian neuronal cultures. The absence of detectable SPT7 in these NIIs may indicate that the integrity of the complexes is disrupted. The decrease in ATXN7T-induced neuronal death obtained with the HDAC inhibitor sodium butyrate in this cellular model strongly suggests that compensation for impaired histone acetylation might be beneficial to patients. An analog of this compound, sodium phenylbutyrate, effective in HD mice (Gardian et al., 2005), is already being tested in a dose-finding phase I study in patients with HD (Borovecki et al., 2005).

In conclusion, we have generated a new inducible neuronspecific Drosophila model of a polyQ disorder that recapitulates some phenotypic features of the human disease: late-onset lethality with little neuronal degeneration, locomotor phenotype reflecting neuronal dysfunction, and nuclear inclusions, in neurons, containing major cell stress response proteins. In addition, because expression of ATXN7T-102Q could be reversed in this system, leading to disaggregation of the inclusions and restoration of locomotor function, we were able to show the potential of this model for the development of therapeutic strategies. The quantitative testing of candidate modifier genes made possible by this model has already identified potentially effective therapeutic targets, such as histone acetylation. This was further supported by partial relocation of proteins of the TFTC/STAGA complexes to NIIs and increased survival in response to an HDAC inhibitor in primary mammalian neuronal cultures.

\section{References}

Becher MW, Kotzuk JA, Sharp AH, Davies SW, Bates GP, Price DL, Ross CA (1998) Intranuclear neuronal inclusions in Huntington's disease and dentatorubral and pallidoluysian atrophy: correlation between the density of inclusions and IT15 CAG triplet repeat length. Neurobiol Dis 4:387-397.

Borovecki F, Lovrecic L, Zhou J, Jeong H, Then F, Rosas HD, Hersch SM, Hogarth P, Bouzou B, Jensen RV, Krainc D (2005) Genome-wide expression profiling of human blood reveals biomarkers for Huntington's disease. Proc Natl Acad Sci USA 102:11023-11028.

Brand AH, Perrimon N (1993) Targeted gene expression as a means of altering cell fates and generating dominant phenotypes. Development 118:401-415.

Cancel G, Duyckaerts C, Holmberg M, Zander C, Yvert G, Lebre AS, Ruberg M, Faucheux B, Agid Y, Hirsch E, Brice A (2000) Distribution of ataxin-7 in normal human brain and retina. Brain 123:2519-2530.

Clark HB, Burright EN, Yunis WS, Larson S, Wilcox C, Hartman B, Matilla A, Zoghbi HY, Orr HT (1997) Purkinje cell expression of a mutant allele of SCA1 in transgenic mice leads to disparate effects on motor behaviors, followed by a progressive cerebellar dysfunction and histological alterations. J Neurosci 17:7385-7395.

David G, Abbas N, Stevanin G, Durr A, Yvert G, Cancel G, Weber C, Imbert G, Saudou F, Antoniou E, Drabkin H, Gemmill R, Giunti P, Benomar A, Wood N, Ruberg M, Agid Y, Mandel JL, Brice A (1997) Cloning of the SCA7 gene reveals a highly unstable CAG repeat expansion. Nat Genet 17:65-70.

Davies SW, Turmaine M, Cozens BA, DiFiglia M, Sharp AH, Ross CA, Scherzinger E, Wanker EE, Mangiarini L, Bates GP (1997) Formation of neuronal intranuclear inclusions underlies the neurological dysfunction in mice transgenic for the HD mutation. Cell 90:537-548.

Del Favero J, Krols L, Michalik A, Theuns J, Lofgren A, Goossens D, Wehnert A, Van den BD, Van Zand K, Backhovens H, van Regenmorter N, Martin JJ, Van Broeckhoven C (1998) Molecular genetic analysis of autosomal dominant cerebellar ataxia with retinal degeneration (ADCA type II) caused by CAG triplet repeat expansion. Hum Mol Genet 7:177-186.

Ellerby L, Andrusiak R, Wellington C, Hackam A, Propp S, Wood J, Sharp A, Margolis R, Ross C, Salvesen G, Hayden M, Bredesen D (1999) Cleavage of Atrophin-1 at caspase site aspartic acid 109 modulates cytotoxicity. J Biol Chem 274:8730-8736.

Fernandez-Funez P, Nino-Rosales ML, de Gouyon B, She WC, Luchak JM, 
Martinez P, Turiegano E, Benito J, Capovilla M, Skinner PJ, McCall A, Canal I, Orr HT, Zoghbi HY, Botas J (2000) Identification of genes that modify ataxin-1-induced neurodegeneration. Nature 408:101-106.

Ferrante RJ, Kubilus JK, Lee J, Ryu H, Beesen A, Zucker B, Smith K, Kowall NW, Ratan RR, Luthi-Carter R, Hersch SM (2003) Histone deacetylase inhibition by sodium butyrate chemotherapy ameliorates the neurodegenerative phenotype in Huntington's disease mice. J Neurosci 23:9418-9427.

Garden GA, Libby RT, Fu YH, Kinoshita Y, Huang J, Possin DE, Smith AC, Martinez RA, Fine GC, Grote SK, Ware CB, Einum DD, Morrison RS, Ptacek LJ, Sopher BL, La Spada AR (2002) Polyglutamine-expanded ataxin-7 promotes non-cell-autonomous Purkinje cell degeneration and displays proteolytic cleavage in ataxic transgenic mice. J Neurosci 22:4897-4905.

Garden GA, Truant R, Ellerby L, La Spada AR (2006) Spinocerebellar ataxia type 7: clinical features to cellular pathogenesis. In: Genetic instabilities and neurological diseases (Wells RD, Ashizawa T, eds), pp 399-416. San Diego: Academic.

Gardian G, Browne SE, Choi DK, Klivenyi P, Gregorio J, Kubilus JK, Ryu H, Langley B, Ratan RR, Ferrante RJ, Beal MF (2005) Neuroprotective effects of phenylbutyrate in the N171-82Q transgenic mouse model of Huntington's disease. J Biol Chem 280:556-563.

Gargano JW, Martin I, Bhandari P, Grotewiel MS (2005) Rapid iterative negative geotaxis (RING): a new method for assessing age-related locomotor decline in Drosophila. Exp Gerontol 40:386-395.

Gatchel JR, Zoghbi HY (2005) Diseases of unstable repeat expansion: mechanisms and common principles. Nat Rev Genet 6:743-755.

Ghosh S, Feany MB (2004) Comparison of pathways controlling toxicity in the eye and brain in Drosophila models of human neurodegenerative diseases. Hum Mol Genet 13:2011-2018.

Gusella JF, MacDonald ME (2000) Molecular genetics: unmasking polyglutamine triggers in neurodegenerative disease. Nat Rev Neurosci 1:109-115.

Helmlinger D, Abou-Sleymane G, Yvert G, Rousseau S, Weber C, Trottier Y, Mandel JL, Devys D (2004a) Disease progression despite early loss of polyglutamine protein expression in SCA7 mouse model. J Neurosci 24:1881-1887.

Helmlinger D, Hardy S, Sasorith S, Klein F, Robert F, Weber C, Miguet L, Potier N, Van Dorsselaer A, Wurtz JM, Mandel JL, Tora L, Devys D (2004b) Ataxin-7 is a subunit of GCN5 histone acetyltransferasecontaining complexes. Hum Mol Genet 13:1257-1265.

Helmlinger D, Hardy S, Abou-Sleymane G, Eberlin A, Bowman AB, Gansmuller A, Picaud S, Zoghbi HY, Trottier Y, Tora L, Devys D (2006) Glutamine-expanded ataxin-7 alters TFTC/STAGA recruitment and chromatin structure leading to photoreceptor dysfunction. PLoS Biol 4:e67.

Holmberg M, Duyckaerts C, Durr A, Cancel G, Gourfinkel-An I, Damier P, Faucheux B, Trottier Y, Hirsch EC, Agid Y, Brice A (1998) Spinocerebellar ataxia type 7 (SCA7): a neurodegenerative disorder with neuronal intranuclear inclusions. Hum Mol Genet 7:913-918.

Imbert G, Saudou F, Yvert G, Devys D, Trottier Y, Garnier JM, Weber C, Mandel JL, Cancel G, Abbas N, Durr A, Didierjean O, Stevanin G, Agid Y, Brice A (1996) Cloning of the gene for spinocerebellar ataxia 2 reveals a locus with high sensitivity to expanded CAG/glutamine repeats. Nat Genet 14:285-291.

Jackson GR, Salecker I, Dong X, Yao X, Arnheim N, Faber PW, MacDonald ME, Zipursky SL (1998) Polyglutamine-expanded human huntingtin transgenes induce degeneration of Drosophila photoreceptor neurons. Neuron 21:633-642.

Jackson SM, Whitworth AJ, Greene JC, Libby RT, Baccam SL, Pallanck LJ, La Spada AR (2005) A SCA7 CAG/CTG repeat expansion is stable in Drosophila melanogaster despite modulation of genomic context and gene dosage. Gene 347:35-41.

Jassim OW, Fink JL, Cagan RL (2003) Dmp53 protects the Drosophila retina during a developmentally regulated DNA damage response. EMBO J 22:5622-5632.

Kazemi-Esfarjani P, Benzer S (2000) Genetic suppression of polyglutamine toxicity in Drosophila. Science 287:1837-1840.

Klement IA, Skinner PJ, Kaytor MD, Yi H, Hersch SM, Clark HB, Zoghbi HY, Orr HT (1998) Ataxin-1 nuclear localization and aggregation: role in polyglutamine-induced disease in SCA1 transgenic mice. Cell 95:41-53.

Koob MD, Benzow KA, Bird TD, Day JW, Moseley ML, Ranum LP (1998)
Rapid cloning of expanded trinucleotide repeat sequences from genomic DNA. Nat Genet 18:72-75.

La Spada AR, Fu YH, Sopher BL, Libby RT, Wang X, Li LY, Einum DD, Huang J, Possin DE, Smith AC, Martinez RA, Koszdin KL, Treuting PM, Ware CB, Hurley JB, Ptacek LJ, Chen S (2001) Polyglutamine-expanded ataxin-7 antagonizes CRX function and induces cone-rod dystrophy in a mouse model of SCA7. Neuron 31:913-927.

Latouche M, Fragner P, Martin E, El Hachimi KH, Zander C, Sittler A, Ruberg M, Brice A, Stevanin G (2006) Polyglutamine and polyalanine expansions in ataxin7 result in different types of aggregation and levels of toxicity. Mol Cell Neurosci 31:438-445.

Lin DM, Goodman CS (1994) Ectopic and increased expression of Fasciclin II alters motoneuron growth cone guidance. Neuron 13:507-523.

Mangiarini L, Sathasivam K, Seller M, Cozens B, Harper A, Hetherington C, Lawton M, Trottier Y, Lehrach H, Davies SW, Bates GP (1996) Exon 1 of the HD gene with an expanded CAG repeat is sufficient to cause a progressive neurological phenotype in transgenic mice. Cell 87:493-506.

Marsh JL, Walker H, Theisen H, Zhu YZ, Fielder T, Purcell J, Thompson LM (2000) Expanded polyglutamine peptides alone are intrinsically cytotoxic and cause neurodegeneration in Drosophila. Hum Mol Genet 9:13-25.

Martin-Aparicio E, Yamamoto A, Hernandez F, Hen R, Avila J, Lucas JJ (2001) Proteasomal-dependent aggregate reversal and absence of cell death in a conditional mouse model of Huntington's disease. J Neurosci 21:8772-8781.

McMahon SJ, Pray-Grant MG, Schieltz D, Yates III JR, Grant PA (2005) Polyglutamine-expanded spinocerebellar ataxia-7 protein disrupts normal SAGA and SLIK histone acetyltransferase activity. Proc Natl Acad Sci USA 102:8478-8482.

Minamiyama M, Katsuno M, Adachi H, Waza M, Sang C, Kobayashi Y, Tanaka F, Doyu M, Inukai A, Sobue G (2004) Sodium butyrate ameliorates phenotypic expression in a transgenic mouse model of spinal and bulbar muscular atrophy. Hum Mol Genet 13:1183-1192.

Muriel MP, Bernard V, Levey AI, Laribi O, Abrous DN, Agid Y, Bloch B, Hirsch EC (1999) Levodopa induces a cytoplasmic localization of D1 dopamine receptors in striatal neurons in Parkinson's disease. Ann Neurol 46:103-111.

Nishitoh H, Matsuzawa A, Tobiume K, Saegusa K, Takeda K, Inoue K, Hori S, Kakizuka A, Ichijo H (2002) ASK1 is essential for endoplasmic reticulum stress-induced neuronal cell death triggered by expanded polyglutamine repeats. Genes Dev 16:1345-1355.

Osterwalder T, Yoon KS, White BH, Keshishian H (2001) A conditional tissue-specific transgene expression system using inducible GAL4. Proc Natl Acad Sci USA 98:12596-12601.

Palhan VB, Chen S, Peng GH, Tjernberg A, Gamper AM, Fan Y, Chait BT, La Spada AR, Roeder RG (2005) Polyglutamine-expanded ataxin-7 inhibits STAGA histone acetyltransferase activity to produce retinal degeneration. Proc Natl Acad Sci USA 102:8472-8477.

Pulst SM, Nechiporuk A, Nechiporuk T, Gispert S, Chen XN, Lopes-Cendes I, Pearlman S, Starkman S, Orozco-Diaz G, Lunkes A, DeJong P, Rouleau GA, Auburger G, Korenberg JR, Figueroa C, Sahba S (1996) Moderate expansion of a normally biallelic trinucleotide repeat in spinocerebellar ataxia type 2. Nat Genet 14:269-276.

Ralser M, Albrecht M, Nonhoff U, Lengauer T, Lehrach H, Krobitsch S (2005a) An integrative approach to gain insights into the cellular function of human ataxin-2. J Mol Biol 346:203-214.

Ralser M, Nonhoff U, Albrecht M, Lengauer T, Wanker EE, Lehrach H, Krobitsch S (2005b) Ataxin-2 and huntingtin interact with endophilin-A complexes to function in plastin-associated pathways. Hum Mol Genet 14:2893-2909.

Ravikumar B, Vacher C, Berger Z, Davies JE, Luo S, Oroz LG, Scaravilli F, Easton DF, Duden R, O'Kane CJ, Rubinsztein DC (2004) Inhibition of mTOR induces autophagy and reduces toxicity of polyglutamine expansions in fly and mouse models of Huntington disease. Nat Genet 36:585-595.

Regulier E, Trottier Y, Perrin V, Aebischer P, Deglon N (2003) Early and reversible neuropathology induced by tetracycline-regulated lentiviral overexpression of mutant huntingtin in rat striatum. Hum Mol Genet 12:2827-2836.

Roon-Mom WM, Reid SJ, Faull RL, Snell RG (2005) TATA-binding protein in neurodegenerative disease. Neuroscience 133:863-872.

Sanpei K, Takano H, Igarashi S, Sato T, Oyake M, Sasaki H, Wakisaka A, 
Tashiro K, Ishida Y, Ikeuchi T, Koide R, Saito M, Sato A, Tanaka T, Hanyu S, Takiyama Y, Nishizawa M, Shimizu N, Nomura Y, Segawa M, et al. (1996) Identification of the spinocerebellar ataxia type 2 gene using a direct identification of repeat expansion and cloning technique, DIRECT. Nat Genet 14:277-284.

Sathasivam K, Hobbs C, Turmaine M, Mangiarini L, Mahal A, Bertaux F, Wanker EE, Doherty P, Davies SW, Bates GP (1999) Formation of polyglutamine inclusions in non-CNS tissue. Hum Mol Genet 8:813-822.

Satterfield TF, Jackson SM, Pallanck LJ (2002) A Drosophila homolog of the polyglutamine disease gene SCA2 is a dosage-sensitive regulator of actin filament formation. Genetics 162:1687-1702.

Saudou F, Finkbeiner S, Devys D, Greenberg ME (1998) Huntingtin acts in the nucleus to induce apoptosis but death does not correlate with the formation of intranuclear inclusions. Cell 95:55-66.

Scherzinger E, Lurz R, Turmaine M, Mangiarini L, Hollenbach B, Hasenbank R, Bates GP, Davies SW, Lehrach H, Wanker EE (1997) Huntingtinencoded polyglutamine expansions form amyloid-like protein aggregates in vitro and in vivo. Cell 90:549-558.

Scherzinger E, Sittler A, Schweiger K, Heiser V, Lurz R, Hasenbank R, Bates GP, Lehrach H, Wanker EE (1999) Self-assembly of polyglutaminecontaining huntingtin fragments into amyloid-like fibrils: implications for Huntington's disease pathology. Proc Natl Acad Sci USA 96:4604-4609.

Shelbourne PF, Killeen N, Hevner RF, Johnston HM, Tecott L, Lewandoski M, Ennis M, Ramirez L, Li Z, Iannicola C, Littman DR, Myers RM (1999) A Huntington's disease CAG expansion at the murine Hdh locus is unstable and associated with behavioural abnormalities in mice. Hum Mol Genet 8:763-774.

Shulman JM, Feany MB (2003) Genetic modifiers of tauopathy in Drosophila. Genetics 165:1233-1242.

Skinner PJ, Koshy BT, Cummings CJ, Klement IA, Helin K, Servadio A, Zoghbi HY, Orr HT (1997) Ataxin-1 with an expanded glutamine tract alters nuclear matrix-associated structures. Nature 389:971-974.

Skinner PJ, Vierra-Green CA, Clark HB, Zoghbi HY, Orr HT (2001) Altered trafficking of membrane proteins in purkinje cells of SCA1 transgenic mice. Am J Pathol 159:905-913.

Steffan JS, Bodai L, Pallos J, Poelman M, McCampbell A, Apostol BL, Kazantsev A, Schmidt E, Zhu YZ, Greenwald M, Kurokawa R, Housman DE, Jackson GR, Marsh JL, Thompson LM (2001) Histone deacetylase inhibitors arrest polyglutamine-dependent neurodegeneration in Drosophila. Nature 413:739-743.

Stevanin G, Durr A, Brice A (2000) Clinical and molecular advances in autosomal dominant cerebellar ataxias: from genotype to phenotype and physiopathology. Eur J Hum Genet 8:4-18.

Strom AL, Forsgren L, Holmberg M (2005) A role for both wild-type and expanded ataxin-7 in transcriptional regulation. Neurobiol Dis 20:646-655.
Takahashi J, Fujigasaki H, Zander C, El Hachimi KH, Stevanin G, Durr A, Lebre AS, Yvert G, Trottier Y, The H, Hauw JJ, Duyckaerts C, Brice A (2002) Two populations of neuronal intranuclear inclusions in SCA7 differ in size and promyelocytic leukaemia protein content. Brain 125:1534-1543.

Takeyama K, Ito S, Yamamoto A, Tanimoto H, Furutani T, Kanuka H, Miura M, Tabata T, Kato S (2002) Androgen-dependent neurodegeneration by polyglutamine-expanded human androgen receptor in Drosophila. Neuron 35:855-864.

Usdin MT, Shelbourne PF, Myers RM, Madison DV (1999) Impaired synaptic plasticity in mice carrying the Huntington's disease mutation. Hum Mol Genet 8:839-846.

Warrick JM, Paulson HL, Gray-Board, Bui QT, Fischbeck KH, Pittman RN, Bonini NM (1998) Expanded polyglutamine protein forms nuclear inclusions and causes neural degeneration in Drosophila. Cell 93:939-949.

Warrick JM, Morabito LM, Bilen J, Gordesky-Gold B, Faust LZ, Paulson HL, Bonini NM (2005) Ataxin-3 suppresses polyglutamine neurodegeneration in Drosophila by a ubiquitin-associated mechanism. Mol Cell $18: 37-48$

Yamamoto A, Lucas JJ, Hen R (2000) Reversal of neuropathology and motor dysfunction in a conditional model of Huntington's disease. Cell 101:57-66.

Ying M, Xu R, Wu X, Zhu H, Zhuang Y, Han M, Xu T (2006) Sodium butyrate ameliorates histone hypoacetylation and neurodegenerative phenotypes in a mouse model for DRPLA. J Biol Chem 281:12580-12586.

Yoo SY, Pennesi ME, Weeber EJ, Xu B, Atkinson R, Chen S, Armstrong DL, Wu SM, Sweatt JD, Zoghbi HY (2003) SCA7 knockin mice model human SCA7 and reveal gradual accumulation of mutant ataxin-7 in neurons and abnormalities in short-term plasticity. Neuron 37:383-401.

Yvert G, Lindenberg KS, Picaud S, Landwehrmeyer GB, Sahel JA, Mandel JL (2000) Expanded polyglutamines induce neurodegeneration and transneuronal alterations in cerebellum and retina of SCA7 transgenic mice. Hum Mol Genet 9:2491-2506.

Yvert G, Lindenberg KS, Devys D, Helmlinger D, Landwehrmeyer GB, Mandel JL (2001) SCA7 mouse models show selective stabilization of mutant ataxin-7 and similar cellular responses in different neuronal cell types. Hum Mol Genet 10:1679-1692.

Zander C, Takahashi J, El Hachimi KH, Fujigasaki H, Albanese V, Lebre AS, Stevanin G, Duyckaerts C, Brice A (2001) Similarities between spinocerebellar ataxia type 7 (SCA7) cell models and human brain: proteins recruited in inclusions and activation of caspase-3. Hum Mol Genet 10:2569-2579.

Zoghbi HY, Orr HT (2000) Glutamine repeats and neurodegeneration. Annu Rev Neurosci 23:217-247.

Zu T, Duvick LA, Kaytor MD, Berlinger MS, Zoghbi HY, Clark HB, Orr HT (2004) Recovery from polyglutamine-induced neurodegeneration in conditional SCA1 transgenic mice. J Neurosci 24:8853-8861. 